NBER WORKING PAPER SERIES

BALANCE-OF-PAYMENTS CRISES AND DEVALUATION

Maurice Obstfeld

Working Paper No. 1103

NATIONAL BUREAU OF ECONOMIC RESEARCH

1050 Massachusetts Avenue

Cambridge MA 02138

April 1983

The research reported here is part of the NBER's research program in International Studies. Any opinions expressed are those of the author and not those of the National Bureau of Economic Research. 


\section{Balance-of-Payments Crises and Devaluation}

\section{Abstract}

The collapse of a fixed exchange rate is typically marked by a sudden balance-of-payments crisis in which "speculators" fleeing from the domestic currency acquire a large portion of the central bank's foreign exchange holdings. Faced with such an attack, the central bank often withdraws temporarily from the foreign exchange market, allowing the exchange rate to float freely before devaluing and returning to a fixed-rate regime. This paper links the timing of the initial speculative attack to the magnitude of the expected devaluation and to the length of the transitional period of floating. An implication of the analysis is that there exist devaluations so sharp and transition periods so short that a crisis must occur the moment the market first learns that the current exchange parity will eventually be altered. For sufficiently long transition periods, the floating exchange rate "overshoots" its new peg before appreciating back toward it; for shorter periods, the rate depreciates monotonically to its new fixed level. Accordingly, the central bank's return to the foreign exchange market can occasion a capital outflow or a capital inflow.

Maurice Obstfeld Department of Economics Columbia University New York, New York 10027

(212) $280-5489$ 


\section{Introduction}

A central bank that tolerates a persistent balance-ofpayments deficit will ultimately find itself unable to peg the exchange rate between domestic and foreign currency. If capital is internationally mobile, the collapse of the fixed exchange rate is typically sparked by a sudden balanceof-payments crisis in which "speculators" fleeing from the domestic currency acquire a large portion of the certral bank's foreign reserve stock. Faced with this reserve hemorrhage, the bank must withdraw from the foreign exchange market and allow the exchange rate to float, at least temporarily.

Can economic theory throw any light on the timing of such speculative attacks? In a perceptive analysis, Krugman [3] demonstrates that when agents have perfect foresight, asset markets can be continuously in equilibrium only if the attack occurs on a unique, well-defined date. I' A balance-of-psyments crisis will generally take place only after the date upon which it first becomes apparent that the fixed exchange rate cannot be defended indefinitely. Roughly speaking, the time of the attack is determined by the requirement that no discrete jump in the equilibrium exchange rate occur at the moment the transition from a fixed to a floating-rate regime is made.

The timing of a crisis thus depends on the policies 
agents expect the central bank to pursue during and after a run on its reserve stock. Krugman [3] analyzes the case in which the bank commits its entire reserve stock to the defense of the currency, and, after losing that stock, never again intervenes to influence the exchange rate. $\underline{\text { / }}$ More frequently, however, a central bank abandons the current exchange rate before the speculators have acquired all its reserves, and then, after a transitional period of floating, re-pegs the rate at a higher level. In other words, the balance-of-payments crisis leads to a devaluation rather than to a permanent abandonment of the fixed exchange rate regime. $\underline{3} /$

This paper studies how the expectation of subsequent devaluation affects the timing of balance-of-payments crises. section I describes a simple open-economy model, and section I uses it to link the date of a crisis to the magnitude of the expected devaluation and the duration of the transitional float. While crises occur earlier the greater the anticipated devaluation, their timing is related to the length of the floating-rate interval in a more complicated way. That relation is explored in section III, which analyzes the exchange rate's behavior during the interlude of floating. An implication of the analysis is that there exist transition periods so short and devaluations so large that a crisis must occur the moment agents discover that the exchange parity will eventually be altered. If a crisis is inevitable and agents learn that the central bank will respond with an immediate devaluation, then the crisis must take place immediately. 


\section{The Model}

The simple linear example used here is taken directly from Flood and Garber [2]. We consider a small open economy whose residents consume a single consumption good supplied by both foreign and domestic producers. Two assets are available, domestic money (which foreigners do not hold) and an internationally tradable bond whose face value in terms of foreign currency is fixed. The domestic money price of the consumption good is denoted by $P$, while the foreign-currency price of consumption is $P^{*}$. The two orices are linked by the arbitrage relation

$$
P=E P^{*},
$$

where E, the exchange rate, is the price of foreign money in terms of home money. $P^{*}$ is exogenous and constant; for convenience, the normalization $P^{*}=1$ is adopted. An additional assumption of convenience is that the interest rate on foreigncurrency bonds is constant and equal to zero.

The demand for domestic real money balances is a decreasing function of the rate of exchange depreciation:

$$
M_{t}^{\alpha} / E_{t}=\alpha-B\left(\dot{E}_{t} / E_{t}\right)
$$

According to (1) and (2), a higher home inflation rate leads 
asset holders to devote a greater share of their portfolios to foreign-currency assets. The supply of domestic money is given by

$$
M_{t}^{s}=D_{t}+R_{t}
$$

where $D_{t}$ is the domestic credit component of the monetary base and $R_{t}$ is the stock of foreign reserves of the central bank, valued in home currency at the exchange rate prevailing on the purchase date. In equilibrium, $M_{t}^{d}=M_{t}^{S}=D_{t}+R_{t}$. The central bank causes domestic credit to evolve over time according to the rule

$$
\dot{\mathrm{D}}_{\mathrm{t}}=\mu>0 \text {. }
$$

Rule (4) is always followed, under all exchange-rate regimes.

Under a fixed exchange rate and with perfect capital mobility, the foreign reserve stock $R_{t}$ is an endogenous variable that can jump discontinuously as private residents re-balance their portfolios in response to current or anticipated shocks. Accordingly, at times $t$ when the reserve stock undergoes a discrete change, the analysis below will distinguish between the left-hand and right-hand limits of the reserve path, denoted by

$$
R_{t}^{-}=\lim _{\substack{s \rightarrow t \\ s<t}} R_{s}, R_{t}^{+}=\lim _{\substack{s \rightarrow t \\ s>t}} R_{s} .
$$


A notational convention similar to (5) will be applied below to other non-predetermined variables. The domestic credit stock is not among these, however: provided the central bank adheres rigidly to rule (4), making no discrete changes in its domestic assets, $D_{t}$ is a predetermined variable and must change continuously. If the exchange rate is initially fixed at level $\bar{E}$, so that $\dot{E} / E=0$, the equilibrium level of nominal balances must, by (2), be constant at level

$$
\overline{\mathrm{M}}=\alpha \overline{\mathrm{E}} \text {. }
$$

By (3) and (4), therefore, official international reserves must decline at rate $\mu$ as long as the exchange rate remains pegged:

$$
\dot{\mathrm{R}}_{t}=-\mu \text {. }
$$

The reserve loss has as its counterpart a continuing privatesector capital outflow; and the fixed exchange rate must be abandoned once the stock of reserves earmarked for defense of the exchange rate $\bar{E}$ has been exhausted. As Krugman [3] observes, the collapse of the exchange rate will involve a balance-ofpayments crisis in which domestic residents suddenly acquire the non-earmarked portion of the central bank's foreign reserve stock.

The precise timing of the crisis depends on the policies agents expect the central bank to adopt in response to a 
run on its reserves. Krugman [3] focuses on the case in which the central bank withdraws permanently from the foreign exchange market after the run; but there are other possibilities. The next section studies how anticipated post-attack policies affect the timing of the speculative attack.

II. Crises and Devaluation

Central banks rarely commit all their reserves to defending an indefensible exchange rate. Typically, the central bank will simply withdraw from the foreign exchange market once a balance-of-payments crisis has driven foreign reserves to a level it deems dangerously low. After a transitional period of floating, the exchange rate is formally devalued and pegged at its new, higher level. The establishment of a "realistic" exchange rate may evoke an initial capital inflow; but unless the devaluation is accompanied by appropriately restrictive macroeconomic measures, further crises will inevitably occur. $\underline{4}$ /

To study how this scenario influences the timing of the initial attack, some assumptions about agents' information are required. It is assumed that the length of the transitional period of floating, denoted by $\tau$, is known with certainty. Further, agents are assumed to know the level $\overline{\mathrm{E}}$ '> $\overline{\mathrm{E}}$ to which the exchange rate will be devalued at the end of the transition. A final piece of information that must be available is the 
reserve level $\bar{R}>0$ at which the monetary authority abandons the current fixed exchange rate. The case emphasized in [3] is the case $\tau=\infty$ in which, following a crisis, the exchange rate is allowed to float freely forever.

Time begins at $t=0$. The time $T$ at which the attack on the exchange rate occurs is calculated, as ususal, by a process of backward induction. The key to the solution is the observation that along a perfect-foresight path, agents can never expect a discrete jump in the level of the exchange rate: a jump, if anticipated, would provide agents with a profitable arbitrage opportunity inconsistent with the hypothesized equilibrium (see [3]). This principle delivers two restrictions on the economy's path. At time $T$, when the central bank allows the exchange rate to float, the initial fixed exchange rate $\bar{E}$ must coincide with the exchange rate $E_{T}$ equilibrating the asset markets. Further, as $t$ approaches $T+\tau$ (the moment at which the central bank re-erters the foreign exchange market) the equilibrium floating exchange rate $E_{t}$ must converge to the new par value, $\bar{E}^{\prime}$. Only the depreciation rate $\dot{E} / E$ can jump.

Consider first the behavior of the exchange rate during the transitional period of floating. That behavior is governed by equation (2). A general solution to the non-autonomous differential equation defined by (2) is

$$
E_{t}=k e^{\alpha t / B}+\underset{B}{T} \int_{s}^{T+\tau}\left(D_{s}+\bar{R}\right) e^{-\alpha(s-t) / B} d s \quad(T \leq t<T+\tau),
$$


where $k$ is an arbitrary constant. Note that $\bar{R}=R_{T}^{+}$, while reserves $R_{T}^{-}-\bar{R}$ are lost in the attack. The particular solution of (2) associated with asset-market equilibrium can be determined by invoking the necessary terminal condition $\mathrm{E}_{\mathrm{T}+\tau}^{-}=\overline{\mathrm{E}}^{\prime}$; and the unique value of $k$ consistent with this terminal condition is, by $(8), k=\bar{E}^{\prime} e^{-\alpha(T+\tau) / B}$. The path of the exchange rate during the transition period is therefore described by

$$
E_{t}=\bar{E} \cdot e^{\alpha(t-T-\tau) / \beta}+\frac{I}{\beta} \int_{t}^{T+\tau}\left(D_{s}+\bar{R}\right) e^{-\alpha(s-t) / \beta} d s
$$

By equating the original fixed exchange rate $\vec{E}$ to the value for $E_{T}^{+}$given by ( 9 ), the time $T$ at which the balance-ofpayments crisis occurs can be calculated. A convenient expression for $E_{T}^{+}$is obtained by setting $t=T$ in (9), integrating by parts, and applying (4):

$$
\begin{aligned}
E_{T}^{+}= & \bar{E} \cdot e^{-\alpha \tau / \beta}+\frac{\beta \mu}{\alpha 2}\left(1-e^{-\alpha \tau / B}\right)+\frac{1}{\alpha}\left(D_{T}+\bar{R}\right)\left(1-e^{-\alpha \tau / \beta}\right) \\
& -\frac{\mu \tau}{\alpha} e^{-\alpha \tau / \beta} .
\end{aligned}
$$

To find $T$, equate the right-hand side of (10) to $\bar{E}$ and substitute $D_{0}+\mu T$ for $D_{T}$. The date of the speculative attack is given by

$$
T=\frac{[\mu \tau-\alpha(\bar{E},-\bar{E})] e^{-\alpha \tau / \beta}}{\mu\left(1-e^{-\alpha \tau / \beta}\right)}+\frac{\alpha \bar{E}-D_{0}-\bar{R}}{\mu}-\frac{\beta}{\alpha} .
$$


Expression ( $I I$ ) shows how the anticipated official response to a balance-of-payments crisis influences the date of its occurrence. The equilibrium value of $T$ is clearly $a$ declining function of $\bar{E}$ ', the anticipated post-devaluation exchange rate; thus, the greater the expected devaluation, the sooner the speculative attack occurs. Indeed, there exist devaluations sufficiently drastic that $T \leq 0$. In these cases, the currency is attacked the moment the market learns that the fixed exchange rate cannot be maintained forever. The relation between $T$ and $\tau$ is more complex, and is graphed in Figure I; for future reference,

$$
\frac{d T}{d \tau}=\frac{\mu\left(I-e^{-\alpha \tau / B}\right)-(\alpha / \beta)[\mu \tau-\alpha(\bar{E} \cdot-\bar{E})]}{\mu e^{\alpha \tau / B}\left(I-e^{-\alpha \tau / B}\right)^{2}} .
$$

An intuitive explanation of Figure 1 is most easily given after the next section's discussion of exchange rate behavior during the floating-rate interlude. Note, however, that as $t \rightarrow 0, T+-\infty$, so that a run must occur at time 0 if the transitional period $\tau$ is sufficiently short. $/$ / In particular, if it is known that the monetary authority will devalue the instant the attack takes place $(\tau=0)$, the run must occur as soon as the inevitability of a crisis is perceived. When the exchange rate is to be sharply devalued with no transitional 


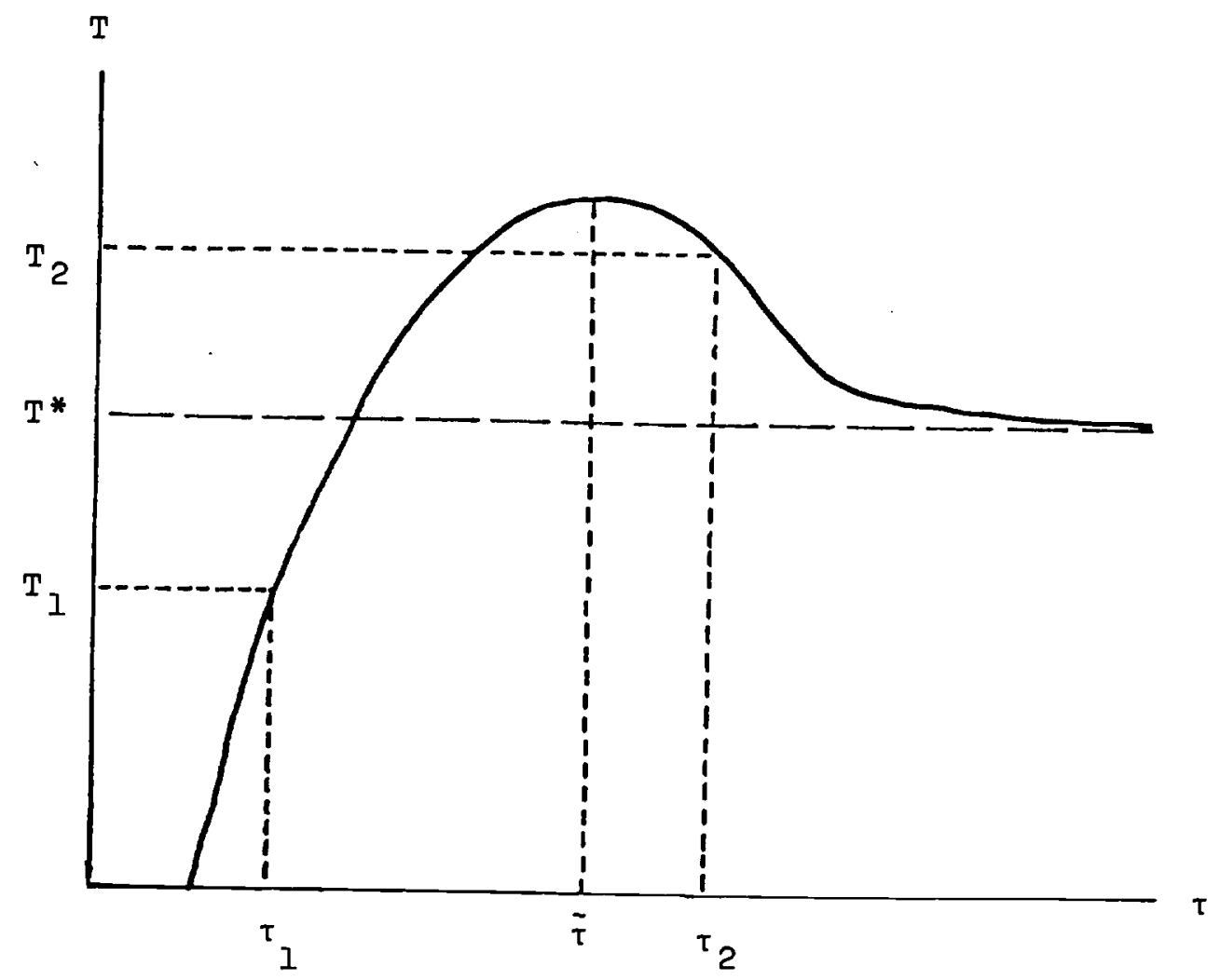

FIGURE I 
float, domestic money holders can avold an anticipated discrete capital loss only if they stage an immediate attack.

III. Exchange Rate Dynamics during the Transition Period

A useful benchmark for the purposes of this section is the case $\tau=\infty$ studied in [2] and in [3]. When the central bank leaves the foreign exchange market forever after the speculative attack, the date of the attack, denoted $T^{*}$, is given by

$$
T^{*}=\frac{\alpha \bar{E}-D_{0}-\bar{R}}{\mu}-\frac{B}{\alpha}
$$

[let $\tau \rightarrow \infty$ in equation (II)]. How does the exchange rate behave after floating in this limiting case? By (9), the exchange rate $E_{t}$ is equal to $\left(D_{t}+\bar{R}\right) / \alpha+\beta \mu / \alpha^{2}$ for $t \geq T^{*}$. It follows that the exchange rate's time derivative $\dot{E}_{t}$ is constant at $\mu / \alpha$ during the (infinite) period of floating following the attack.

Return now to the assumption $\tau<\infty$. If $\mu \tau / \alpha=\bar{E} \cdot-\bar{E}$, then, by (1I) and (13), $T=T^{*}$ : the crisis occurs on the same date as it would if the exchange rate were never re-pegged. The reason for this is that the exchange rate can move from $\bar{E}$ to $\bar{E}$ ' over the transitional period if it rises at the constant rate $\mu / \alpha$ characterizing the case $\tau=\infty$. Because the demand for money the instant after the attack is then the same as in 
the case $\tau=\infty$, the attack must occur at time $T^{*}$. The existence of a finite $\tau$ such that the attack occurs at $T^{*}$ is reflected in Figure 1.

The foregoing transition time is a borderline case. It is now clear that if $\mu \tau / \alpha<\bar{E}^{\prime}-\bar{E}$, the exchange rate must at all moments depreciate more quickly, and at an increasing rate, to travel from to $\overline{E^{\prime}}$ in time $\tau$; thus, $T<T^{*}$, so that real balances are lower than in the borderline case the instant after the attack. Similarly, $T>T^{*}$ when $\mu \tau / \alpha>\bar{E}^{\prime}-\bar{E}$. In the latter situation, $E_{t}$ rises at a declining rate during the float; but the exchange rate may "overshoot" $\overline{E^{\prime}}$ and subsequently appreciate if real balances become sufficiently high. Figure 2 displays two possible exchange rate paths corresponding to the transition times $\tau_{1}$ and $\tau_{2}$ in Figure 1 .

When $\mu \tau / \alpha>\bar{E}^{\prime}-\bar{E}$, the exchange rate may be depreciating (at a falling rate), appreciating (at a rising rate), or stationary at the moment the central bank re-enters the foreign exchange market. In order that the exchange rate be stationary at that moment (i.e., $\dot{\mathrm{E}}_{\mathrm{T}+\tau}^{-}=0$ ), it must be true [by (2)] that $M_{\mathrm{T}+\tau}^{-}=$ $D_{T+\tau}+\bar{R}=\alpha \bar{E}^{\prime}$. Through use of (4) and (II), this condition can be written as

$$
\mu\left(1-e^{-\alpha \tau / \beta}\right)-(\alpha / \beta)[\mu \tau-\alpha(\bar{E} \cdot-\bar{E})]=0 .
$$

Let $\tilde{\tau}$ denote the unique value of $\tau$ satisfying (14). As (12) shows, 


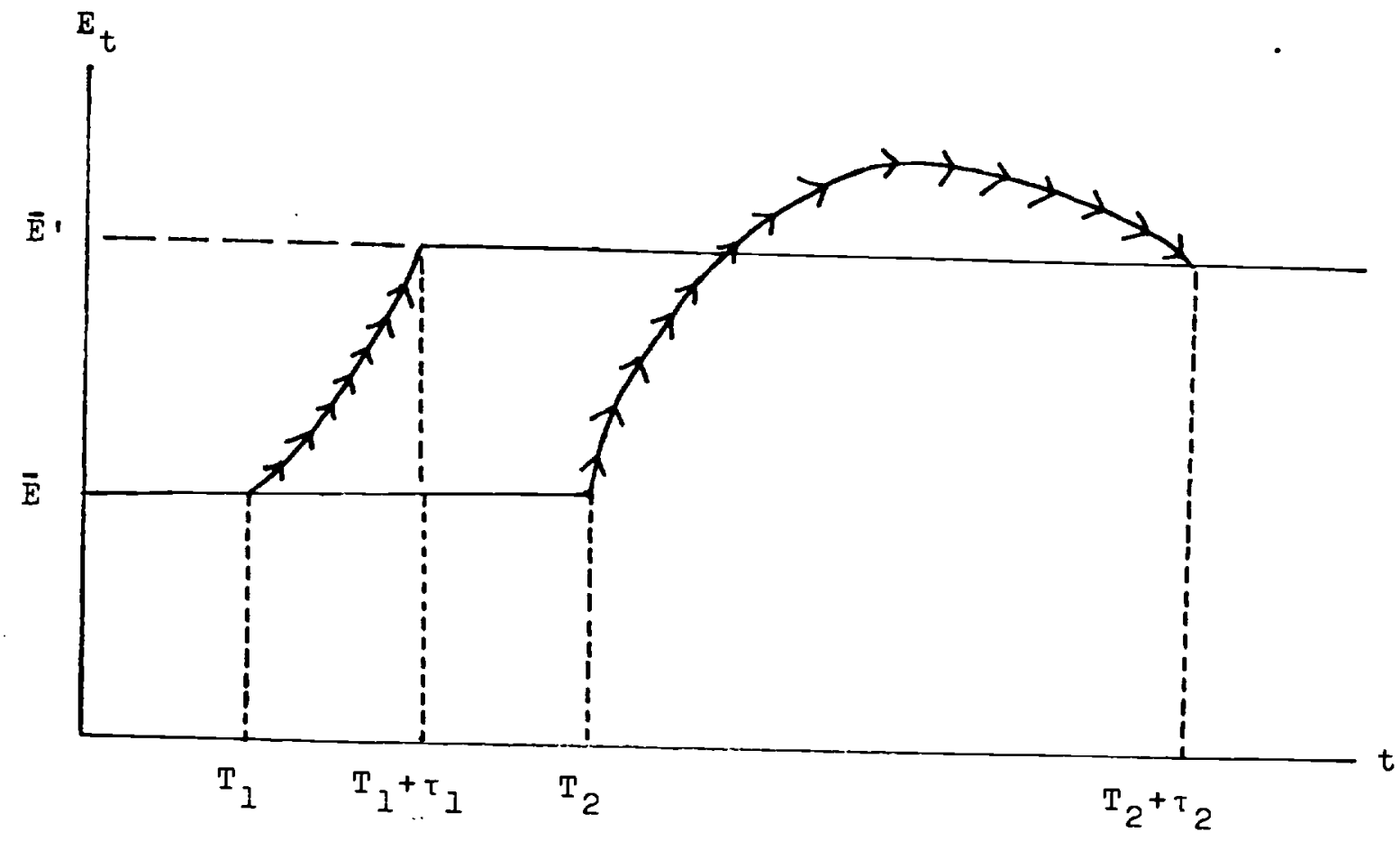

FIGURE? 
$\tilde{\tau}$ is also the transition interval such that $\mathrm{dT} / \mathrm{d} \tau=0$. It is thus the dividing point between cases in which a reduction in $\tau$ hastens the speculative attack and cases in which a reduction in $t$ postpones the attack (see Figure I).

The foregoing coincidence yields some intuition regarding the sign of the derivative $d T / d \tau$. When $\tau<\tilde{\tau}$, the exchange rate depreciates from $\bar{E}$ to $\bar{E}$ ' during the floating period without ever rising above $\bar{E}^{\prime}$. Since a reduction in $\tau$ shortens the time available for this transition, the exchange rate must be depreciating more quickly at the outset; and this can be the case only if the run occurs earlier, so that initial nominal balances $\mathrm{M}_{\mathrm{T}}^{+}$are lower.

When $\tau>\tilde{\tau}$, however, the exchange rate rises above $\vec{E}^{\prime}$ during the floating-rate interlude before appreciating toward $\bar{E}$ ' at an increasing rate (see Figure 2). A fall in $\tau$ again decreases the time available for the transition from $\bar{E}$ to $\bar{E}^{\prime}$; but in the present case, a rise in $T$ makes the transition possible by raising $\mathrm{M}_{\mathrm{T}}^{+}$and thus shortening the initial period (and reducing the extent) of exchange rate depreciation before the rapid appreciation to $\bar{E}$ '.

The central bank's re-entry into the foreign exchange market occasions an equilibrating capital movement. If $\tau<\tilde{\tau}$, implying that $\dot{\mathrm{E}}_{\mathrm{T}+\tau}^{-}>0$, the pegging of the exchange rate must raise money demand, and cause an instantaneous capital inflow (a transfer of foreign assets from the public to the central bank). When $\tau>\tilde{\tau}$, however, $\dot{\mathrm{E}}_{\mathrm{T}+\tau}^{-}<0$, money demand is 
reduced, and the bank suffers a reserve loss. - The benavior of the capital account after devaluation is often linked to the monetary authority's success in choosing a "realistic" exchange rate and adopting appropriately restrictive macroeconomic policies. The present analysis appears to support that view because the longer is the transition period, the higher is the money supply and the less "realistic" is a given exchange rate at the time of re-pegging. Note, however, that a capital inflow may accompany re-pegging even if the market knows that the new fixed exchange rate must eventually be abandoned.

\section{Conciusion}

When a fixed exchange rate is untenable, the centrai bank may devalue rather than exhaust its foreign reserves ir. a futile attempt to defend that rate. This paper has studied how the prospect of devaluation affects the timing of the balance-of-payments crisis that forces the monetary authority's hand. In the model employed above, the date of the crisis is a well-defined function of bctin the magnitude of the expectea devaluation and the leneth of the transitional period of floating preceding the establishment of a new exciange parity. The latter relationship, while understandable, is complex. One simple and important implication is this: if the transitional float is sufficiently brief, a speculative attack on the currency will occur as soon as the market realizes that the current exchange rate cannot be enforced indefinitely. 
The behavior of the exchange rate during the . transitional float elucidates the relationship between the length of the floating-rate interlude and the date of the speculative attack; but that behavior is of independent interest as well. For sufficiently long transition periods, the floating exchange rate will "overshoot" its new peg before appreciating back toward it. For shorter transition periods, the rate will depreciate monotonically toward its new fixed level. Depending on which of these cases obtains, the central bank's return to the foreign exchange market may occasion a capital outflow or a capital inflow. The stage is then set for the next balance-of-payments crisis. 


\section{Footnotes}

1. Salant and Henderson [5] contains an early discussion of speculative attacks under rational expectations, while salant [4] analyzes the phenomenon in more general, possibly stochastic models of official price fixing. Flood and Garber [2] develop the computable linear example employed in this paper, and apply it in a stochastic environment.

2. Krugman also studies a model in which the market is uncertain about the portion of its reserves that the central bank is willing to commit. This paper abstracts from such uncertainty.

3. Instances abound. For example, several OECD countries allowed their exchange rates to float temporarily after the speculative crises that led to the Smithsonian currency realignment of December 1971. Blanco and Garber [1] study a stochastic model of exchange-rate crises in which the size of any devaluation is determined by an endogenous central-bank rule. In contrast to this paper, they assume that devaluation occurs as soon as reserves reach their lower limit: there is no temporary period of floating. The particular form of the rule used to choose the post-crisis fixed exchange rate makes it possible for the pre-crisis rate to be viable in some periods even though agents expect devaluation to occur at the same moment as the speculative attack. 
4. The discussion ignores the (realistic) possibility that the central bank responds to the crisis by imposing capital controls.

5. The exchange rate may, of course, jump upward as a result of an attack that occurs at time 0 .

6. Underlying the analysis is the assumption that $\bar{R}$ is large enough to allow the central bank to re-peg the exchange rate for some non-zero time interval. 


\section{REFERENCES}

[1] BLANCO, HERMINIO and PETER M. GARBER: "Recurrent Devaluation and the Timing of Speculative Attacks." Mimeo, University of Rochester, 1982.

[2] FLOOD, ROBERT P. and PETER M. GARBER: "Collapsing Exchange-Rate Regimes: Some Linear Examples." Journal of International Economics, forthcoming.

[3] KRUGMAN, PAUL: "A Model of Balance-of-Payments Crises." Journal of Money, Credit and Banking 11, (August 1979), $311-325$.

[4] SALANT, STEPHEN W.: "The Vulnerability of Price Stabilization Schemes to Speculative Attack." Journal of Political Economy 91, (February 1983), 1-38.

[5] SALANT, STEPHEN W. and DALE W. HENDERSON: "Market Anticipations of Government Policies and the Price of Gold." Journal of Political Economy 86, (August 1978), 627-648. 